\title{
Expression of HBx and COX-2 in chronic hepatitis $B$, cirrhosis and hepatocellular carcinoma: implication of $\mathrm{HBX}$ in upregulation of COX-2
}

\author{
Alfred S-L Cheng ${ }^{1}$, Henry L-Y Chan ${ }^{1}$, Wai K Leung ${ }^{1}$, Ka F To ${ }^{2}$, Minnie Y-Y Go ${ }^{1}$, \\ John Y-H Chan ${ }^{3}$, Choong T Liew ${ }^{2}$ and Joseph J-Y Sung ${ }^{1}$ \\ ${ }^{1}$ Department of Medicine \& Therapeutics; ${ }^{2}$ Department of Anatomical \& Cellular Pathology and ${ }^{3}$ Department \\ of Clinical Oncology, The Chinese University of Hong Kong, Hong Kong
}

\begin{abstract}
Hepatitis B virus is a major etiological factor of hepatocellular carcinoma, but the underlying mechanisms remain unclear. We have previously demonstrated that upregulation of cyclooxygenase (COX)-2 in chronic hepatitis B persisted despite successful antiviral therapy. In this study, we investigated the relationship between the transactivator HBx and COX-2 in hepatitis B virus-associated chronic liver diseases. Expressions of HBx and COX-2 in tissue specimens were determined by single and double immunohistochemistry. The effects of HBx on COX-2 and prostaglandin $E_{2}$ production were studied by transfection. HBx was expressed in $11 / 11(100 \%)$ of chronic hepatitis B, $23 / 23(100 \%)$ of cirrhosis, and $18 / 23(78 \%)$ of hepatocellular carcinoma, whereas no immunoreactivity was found in four nonalcoholic steato-hepatitis controls. COX-2 expression was also detected in all specimens of liver lesions except in only $29 \%$ of poorly differentiated hepatocellular carcinoma. Significant correlation between $\mathrm{HBx}$ and COX-2 immunoreactivity scores was found in different types of chronic liver diseases (chronic hepatitis $B, r s=0.68$; cirrhosis, $r s=0.57$; hepatocellular carcinoma, rs $=0.45$ ). Double immunohistochemistry showed colocalization of $\mathrm{HBx}$ and COX-2 in hepatic parenchymal cells. Similar to COX-2, there was no significant change in HBx expression in patients with chronic hepatitis B after interferon and lamivudine therapy when hepatitis B virus DNA became undetectable and inflammation subsided. Transfection of Hep3B hepatocellular carcinoma cells with HBX increased COX-2 expression and prostaglandin $\mathrm{E}_{2}$ production. $\mathrm{HBx}$ was localized mainly in the cytoplasm and less in nucleus, as found in the liver lesions. In conclusion, our results strongly suggested that there was a close relationship between $\mathrm{HBx}$ and COX-2. COX-2 might represent an important cellular effector of HBx that contributes to hepatitis B virusassociated hepatocarcinogenesis.
\end{abstract}

Modern Pathology (2004) 17, 1169-1179, advance online publication, 25 June 2004; doi:10.1038/modpathol.3800196

Keywords: chronic hepatitis B; cyclooxygenase-2; hepatocarcinogenesis; X protein of hepatitis B virus

Hepatitis B virus is a major etiological agent of hepatocellular carcinoma; and it increases the risk of developing hepatocellular carcinoma by over 200fold. ${ }^{1}$ The smallest hepatitis $\mathrm{B}$ virus open-reading frame encodes the $\mathrm{X}$ protein of hepatitis $\mathrm{B}$ virus (HBx) that appears to be important for hepatocellular transformation in vitro $^{2}$ and hepatocellular carcinoma formation in transgenic mice. ${ }^{3,4}$ However,

Correspondence: Dr JJ-Y Sung, MD, PhD, Department of Medicine \& Therapeutics, Prince of Wales Hospital, Shatin, New Territories, Hong Kong.

E-mail: joesung@cuhk.edu.hk

Received 13 November 2003; revised and accepted 24 March 2004; published online 25 June 2004 the underlying mechanisms of HBx-mediated oncogenicity remain unclear.

Cyclooxygenase (COX) catalyzes the rate-limiting step of prostaglandin biosynthesis. Two COX isoforms have been identified: COX-1 is expressed constitutively, whereas COX-2 is induced by growth factors, tumor promoters, and cytokines. ${ }^{5}$ Overexpression of COX-2 has been reported in tumors of colon, pancreas, esophagus, and stomach as well as in the corresponding premalignant lesions. ${ }^{6-9}$ Gene deletion studies have demonstrated that COX-2 plays a critical role in the development of intestinal neoplasia. ${ }^{10}$ Using a genetic gain-offunction approach, enhanced COX-2 expression is shown to be sufficient to induce tumorigenesis. ${ }^{11}$ Recently, COX-2 upregulation is also found in 
cirrhosis and well-differentiated hepatocellular carcinoma, but less so in poorly differentiated hepatocellular carcinoma, suggesting that COX-2 is involved in early steps of hepatocarcinogenesis. ${ }^{12,13}$

We have previously demonstrated upregulation of COX-2 in hepatocytes of chronic hepatitis B, which persisted even after successful antiviral therapies. ${ }^{14}$ Therefore, upregulation of COX-2 does not simply reflect inflammatory activity. Instead, it might be related to the presence of hepatitis $\mathrm{B}$ virus genome in the hepatocytes. As both HBx and COX-2 are related to hepatocarcinogenesis, we hypothesized that the integrated HBx gene in host hepatocytes is the cause of COX-2 upregulation. In this study, we investigated (1) the relationship between HBx and COX-2 in chronic liver diseases and (2) in vitro induction of $C O X-2$ gene expression by HBx.

\section{Materials and methods}

\section{Patient Samples}

In all, 23 surgically resected hepatocellular carcinoma tissues with adjacent nontumorous cirrhotic livers and 11 chronic hepatitis B biopsies were used in this study. Each hepatocellular carcinoma was histologically graded into one of three categories: well-differentiated, moderately differentiated, or poorly differentiated, according to the criteria proposed by the Liver Cancer Study Group of Japan. ${ }^{15}$ Six chronic hepatitis B patients received lamivudine $100 \mathrm{mg}$ per day for 1 year and five patients received interferon-alfa 5-10 MU three times per week for 16-24 weeks. Liver biopsy was performed before treatment and follow-up biopsy was performed at second year for patients on lamivudine, and at 1 year post-treatment for patients on interferon. All patients responded to lamivudine or interferon therapy by a sustained hepatitis B e antigen sero-conversion to anti-hepatitis $\mathrm{B}$ e antibodies, disappearance of hepatitis B virus DNA in serum (bDNA assay, Chiron Diagnostic, Emeryville, CA, USA), normalization of alanine aminotransferase and resolution of histological hepatic necro- inflammation (Table 1). Pre- and post-treatment liver biopsies were processed for immunohistochemical staining. The histology activity index ${ }^{16}$ of the specimens was scored by a single pathologist (KFT). Liver biopsy specimens from four nonalcoholic steatohepatitis patients, in whom hepatitis $B$ virus and hepatitis C virus coinfection, autoimmune hepatitis and metabolic diseases were excluded, were used as controls for the study.

\section{Immunohistochemistry}

Liver tissues were fixed in $10 \%$ buffered formalin and embedded in paraffin. Sections $(5 \mu \mathrm{m}$ in thickness) were cut and mounted on 3-aminopropyltriethoxysilane-coated slides (Marienfeld, Badmergentheim, Germany). Sections were deparaffinized and rehydrated to Tris-buffered saline, followed by microwave treatment for $10 \mathrm{~min}$. Endogenous peroxidase activity was blocked with $3 \%$ $\mathrm{H}_{2} \mathrm{O}_{2}$ in methanol for $20 \mathrm{~min}$. Nonspecific binding was blocked with $2 \%$ swine serum (DAKO, Glostrup, Denmark), and then incubated with a rabbit polyclonal antibody to HBx (a gift from Dr Mark A Feitelson, Thomas Jefferson University, Philadelphia, PA, USA) in Tris-buffered saline containing $1 \%$ bovine serum albumin overnight. The specificity of this anti-HBx antibody has been rigorously tested. ${ }^{17}$ Tissue section was incubated with the same buffer without the antibody as negative control. This was followed by biotinylated swine anti-rabbit immunoglobulins (1:200; DAKO) and streptavidin/horseradish peroxidase complex (1:400; DAKO) incubation, both for $45 \mathrm{~min}$. The color was developed in 3,3'-diaminobenzidine (Sigma, St Louis, MO, USA). The sections were then counterstained with Mayer's hematoxylin. As the anti-HBx antibody crossreacts with CK $18,{ }^{18}$ we used a monoclonal anti-human antibody (1:10; DAKO) as an internal control for the immunostaining experiments. Cytokeratin 18 immunoreactivity was only observed in epithelial cells of the bile ducts and bile ductules but not in hepatocyte (data not shown).

Table 1 Serological and histological data of chronic hepatitis B patients upon antiviral treatments

\begin{tabular}{|c|c|c|c|}
\hline & \multicolumn{3}{|c|}{ Antiviral treatment $(\mathrm{n}=11)$} \\
\hline & Pretreatment & Posttreatment & $\mathrm{P}$ \\
\hline HBeAg & + & - & \\
\hline Anti-HBe & - & + & \\
\hline Detectable HBV-DNA & $10 / 11$ & $0 / 11$ & \\
\hline HBV-DNA $(\mathrm{Meq} / \mathrm{ml})^{\mathrm{a}}$ & $56.98(<0.7-1494)$ & $<0.7(<0.7-<0.7)$ & \\
\hline Serum ALT (IU/L) ${ }^{\mathrm{a}}$ & $184(69-613)$ & $30(18-36)$ & $<0.001$ \\
\hline Necro-inflammatory score ${ }^{\mathrm{a}, \mathrm{b}}$ & $8.5(5-11)$ & $2(1-4)$ & $<0.001$ \\
\hline
\end{tabular}


COX-2 immunostaining was performed using a goat polyclonal antibody (1:100; Santa Cruz Biotechnology, Santa Cruz, CA, USA) as previously described. ${ }^{14}$ Anti-COX-2 antibody neutralized by preabsorption with the blocking peptide (five-fold excess by weight, Santa Cruz Biotechnology) served as specificity control.

All specimens stained for HBx and COX-2 were scored by two independent investigators (ASLC, KFT) who were blinded to the patient groups and treatments. The scoring was based on intensity and extensiveness (by percentage population) of the positively stained cells. ${ }^{17}$ Both parameters were scored on a scale of $0-3$ as follows: (a) intensity $(0=$ negative staining, $1=$ weakly positive staining, $2=$ moderately positive staining and $3=$ strongly positive staining) and (b) extensiveness $(0=$ negative, $1=$ positive staining in $<30 \%$ of cells, $2=30-70 \%$ and $3=>70 \%$ ). The score of each specimen was the sum of both parameters.

Double immunostaining was performed using the DAKO EnVision Doublestain System according to the manufacturer's protocol. Briefly, the section was incubated with anti-COX-2 antibody after peroxidase blocking. It was followed by anti-goat immunoperoxidase polymer (Histofine, Tokyo, Japan) incubation and the signal was subsequently developed in 3,3'-diaminobenzidine solution. After nonspecific blocking, the section was further incubated with anti-HBx antibody and alkaline phosphatase-labeled polymer. The HBx signal was developed in nitroblue tetrazolium solution (Roche, Indianapolis, IN, USA).

\section{Plasmids}

The $H B x$ open-reading frame was amplified from hepatitis B virus adw2 subtype (Eurohep hepatitis B virus standard, Gottingen, Germany) and engineered to contain flanking EcoRI and SalI restriction sites. The PCR product was digested with the restriction enzymes and the EcoRI-SalI HBx fragment was ligated into pEGFP-C1 or pIRES2-EGFP plasmid (CLONTECH, Palo Alto, CA, USA). The resulting plasmid (pEGFP-C1-HBx or pIRES2-EGFP-HBx) expressed enhanced green fluorescent protein (EGFP) as reporter for HBx expression. The pIRES2-EGFP$\mathrm{HBx}$ plasmid was then digested with EcoRI in combination with SmaI and ligated with a larger fragment of pcDNA3 (Invitrogen, Carlsbad, CA, USA), which was double-digested with EcoRI and $E c o R V$. In the final plasmid pcDNA3-HBx, $H B x$ gene was under the control of cytomegalovirus promoter.

\section{Cell Culture}

Hep3B cells (American Type Culture Collection, Rockville, MD, USA) were used in this study, which was derived from hepatocellular carcinoma and carrying integrated-hepatitis B virus DNA in the genome. The cells were grown in Dulbecco's modified Eagle medium (Invitrogen) supplemented with $10 \%$ heat-inactivated fetal bovine serum (Invitrogen) and $100 \mathrm{U} / \mathrm{ml}$ penicillin and $100 \mu \mathrm{g} / \mathrm{ml}$ streptomycin (Invitrogen). Hep3B cells $\left(3 \times 10^{5}\right)$ were plated in $35-\mathrm{mm}$ dishes and maintained in a humidified atmosphere of $95 \%$ air and $5 \% \mathrm{CO}_{2}$ at $37^{\circ} \mathrm{C}$. In some dishes, Hep3B cells were applied to coverslips placed on the bottom prior to cell seeding.

\section{Transfection}

LipofectAMINE PLUS Reagent (Invitrogen) was used in the transfection experiments. After overnight growth, Hep3B cells were incubated with serum-free medium containing $10 \mu \mathrm{g}$ of pEGFP-C1HBx or pcDNA3-HBx plasmid DNA and transfection reagents for $5 \mathrm{~h}$. After incubation, the transfection medium containing the complexes was replaced with medium supplemented with $10 \%$ fetal bovine serum. The RNA and protein were extracted at 24 and $48 \mathrm{~h}$ after the start of transfection. The cells applied on the coverslips were fixed by methanol and the intracellular distribution of EGFP or EGFPHBx was examined by fluorescence microscopy. Sham-transfection with pEGFP-C1 or pcDNA3 plasmid served as control.

\section{Reverse Transcription-Polymerase Chain Reaction (RT-PCR)}

Total RNA and protein were isolated from Hep3B cells using Trizol reagent (Invitrogen). A measure of $2 \mu \mathrm{g}$ of RNA from each sample was incubated for $10 \mathrm{~min}$ at $65^{\circ} \mathrm{C}$ and then cooled for $2 \mathrm{~min}$ at $4^{\circ} \mathrm{C}$. Subsequently, the RNA was reverse-transcribed for $1 \mathrm{~h}$ at $37^{\circ} \mathrm{C}$ in a $20 \mu \mathrm{l}$ reaction mix containing $1 \times$ reverse transcription buffer (Invitrogen), $5 \mathrm{mM}$ $\mathrm{MgCl}_{2}$ (Invitrogen), $1 \mathrm{mM}$ dNTPs (Invitrogen), $0.4 \mu \mathrm{l}$ random primer (Invitrogen), $1.5 \mathrm{U}$ of AMV reverse transcriptase (Invitrogen) and $16 \mathrm{U}$ of RNasin RNA inhibitor (Promega, Madison, WI, USA). The reaction was terminated after $5 \mathrm{~min}$ at $96^{\circ} \mathrm{C}$. In total, $5 \%$ of the newly synthesized cDNA $(1 \mu \mathrm{l})$ was amplified in a $30-\mu$ l reaction mixture containing $1 \times$ reaction buffer (Invitrogen), $2 \mathrm{mM} \quad \mathrm{MgCl}_{2}$ (Invitrogen), $0.25 \mathrm{mM}$ dNTPs (MBI Fermentas, Vilnius, Lithuania), $0.2 \mathrm{mM}$ of $H B x$ forward and reverse primers and $0.75 \mathrm{U}$ of Taq polymerase (Amersham, Buckinghamshire, England) for 35 cycles (conditions per cycle: $94^{\circ} \mathrm{C}, 1 \mathrm{~min} ; 68^{\circ} \mathrm{C}, 30 \mathrm{~s} ; 72^{\circ} \mathrm{C}, 1.5 \mathrm{~min}$ ). The HBx forward and reverse primer sequences are 5'-CCGGAATTCATGGCTGCTAGGC-3' and $5^{\prime}$-GACGCGTCGACTTAGGCAGAGGTGAAAA $3^{\prime}$, respectively. COX-2 was amplified in the same reaction mix except the primers: 5'-TTCAAATGAGATTGTGGGAAAATTGCT-3' (forward) and $5^{\prime}$ AGATCATCTCTGCCTGAGTATCTT-3' (reverse) for 35 cycles (conditions per cycle: $96^{\circ} \mathrm{C}, 24 \mathrm{~s} ; 58^{\circ} \mathrm{C}$, $\left.48 \mathrm{~s} ; 72^{\circ} \mathrm{C}, 1 \mathrm{~min}\right) . \quad \beta$-Actin was also amplified to 
assess the equality of RNA amount in each sample. ${ }^{14}$ The sizes of the PCR products of $H B x, C O X-2$, and $\beta$ actin were 485, 305, and 654 base-pair, respectively.

\section{Western Blot Analysis}

Protein was dissolved in 1\% SDS with protease inhibitor cocktail (Roche) and protein concentration was measured by the method of Lowry (Bio-Rad, Hercules, CA, USA). A measure of $50 \mu \mathrm{g}$ of protein was loaded per lane, separated by $10 \%$ SDSpolyacrylamide gel electrophoresis under reducing conditions, and transferred onto equilibrated polyvinylidene difluoride membrane (Amersham) by electroblotting. Membranes were blocked by 5\% nonfat dry milk in Tris-buffered saline for overnight. HBx protein was detected with a monoclonal antibody against HBx (Chemicon, Temecula, CA, USA) at a dilution of 1:500 at RT for $2.5 \mathrm{~h}$. After $45 \mathrm{~min}$ of anti-mouse-horseradish peroxidase antibody incubation (1:1000; Santa Cruz Biotechnology), enhanced chemiluminescence (Pierce, Rockford, IL, USA) was determined by exposure to X-ray film (Fuji, Dusseldorf, Germany). Western blot for $\beta$-actin was also performed as an internal (sample loading) control using a monoclonal antibody (Sigma) (data not shown).

\section{Prostaglandin $\mathrm{E}_{2}$ Analysis}

Prostaglandin $\mathrm{E}_{2}$ was purified from the culture supernatant using the Amprep C18 minicolumn (Amersham) and measured by the Biotrak Prostaglandin $\mathrm{E}_{2}$ competitive enzyme immunoassay system (Amersham) according to the manufacturer's instructions.

\section{Statistical Analysis}

The relationships among HBx and COX-2 immunoreactivities in different types of chronic liver diseases, as well as with differentiation status of hepatocellular carcinoma specimens were compared by Spearman's rho test. Two-tailed Mann-Whitney $U$-test was used to compare the serum ALT levels, necro-inflammatory score, fibrosis score, $\mathrm{HBx}$ and COX-2 immunoreactivities between the pre- and post-treatment liver specimens. Statistical significance was taken at $P<0.05$.

\section{Results}

Expressions of HBx and COX-2 in Chronic Hepatitis B, Cirrhosis, and Hepatocellular Carcinoma

Immunohistochemistry showed that $\mathrm{HBx}$ was expressed in $100 \%(11 / 11)$ of chronic hepatitis B, $100 \%(23 / 23)$ of cirrhosis, and $78 \%(18 / 23)$ of hepatocellular carcinoma specimens (Table 2). Among the hepatocellular carcinoma specimens, all $(5 / 5)$ well-differentiated hepatocellular carcinoma expressed HBx, while $82 \%$ (9/11) of moderately and $57 \%(4 / 7)$ of poorly differentiated hepatocellular carcinoma had HBx expression. HBx immunoreactivity was observed mainly in the cytoplasm of hepatic parenchymal cells of chronic hepatitis B (Figure 1), cirrhosis, and neoplastic cells of hepatocellular carcinoma tissues (Figure 2). Nuclear staining of $\mathrm{HBx}$ was uncommon.

In chronic hepatitis B specimens ( $>80 \%), \mathrm{HBx}$ immunoreactivity was detected in more than $30 \%$ of liver cells (Figure 1a and b). Tissue section was negative when primary antibody was omitted (data not shown). In all, four nonalcoholic steato-hepatitis

Table 2 Expressions of HBx and COX-2 in liver specimens from different types of chronic liver diseases

\begin{tabular}{|c|c|c|c|c|c|c|c|c|}
\hline & \multirow[t]{2}{*}{ Number tested } & \multirow[t]{2}{*}{$\%$ of + ve cases } & \multicolumn{3}{|c|}{ Frequency (\%) } & \multicolumn{3}{|c|}{ Intensity (\%) } \\
\hline & & & $<30 \%$ & $30-70 \%$ & $>70 \%$ & + & ++ & +++ \\
\hline \multicolumn{9}{|l|}{$H B x$} \\
\hline Chronic hepatitis B & 11 & 100 & 18.2 & 27.3 & 54.5 & 54.5 & 45.5 & 0 \\
\hline Cirrhosis & 23 & 100 & 56.5 & 34.8 & 8.7 & 47.8 & 52.2 & 0 \\
\hline \multicolumn{9}{|c|}{ Hepatocellular carcinoma } \\
\hline Total & 23 & 78.3 & 47.8 & 26.1 & 4.3 & 56.5 & 21.7 & 0 \\
\hline Well-diff & 5 & 100 & 40 & 40 & 20 & 60 & 40 & 0 \\
\hline Moderately diff & 11 & 81.8 & 54.5 & 27.3 & 0 & 54.5 & 27.3 & 0 \\
\hline Poorly diff & 7 & 57.1 & 42.9 & 14.3 & 0 & 57.1 & 0 & 0 \\
\hline \multicolumn{9}{|l|}{$C O X-2$} \\
\hline Chronic hepatitis B & 11 & 100 & 0 & 9.1 & 90.9 & 54.5 & 45.5 & 0 \\
\hline Cirrhosis & 23 & 100 & 34.8 & 47.8 & 17.4 & 65.2 & 34.8 & 0 \\
\hline \multicolumn{9}{|c|}{ Hepatocellular carcinoma } \\
\hline Total & 23 & 78.3 & 47.8 & 21.7 & 8.7 & 69.6 & 8.7 & 0 \\
\hline Well-diff & 5 & 100 & 20 & 60 & 20 & 80 & 20 & 0 \\
\hline Moderately diff & 11 & 100 & 72.7 & 18.2 & 9.1 & 90.9 & 9.1 & 0 \\
\hline Poorly diff & 7 & 28.6 & 28.6 & 0 & 0 & 28.6 & 0 & 0 \\
\hline
\end{tabular}

Diff, differentiated. 
patients, HBx immunoreactivity was not found in hepatocyte and thus further validated the specificity of anti-HBx antibody (Figure 1c). Over $40 \%$ of cirrhosis specimens showed HBx expression in more than $30 \%$ of liver cells (Figure 2a and b). Among the hepatocellular carcinoma tissues, 60\%
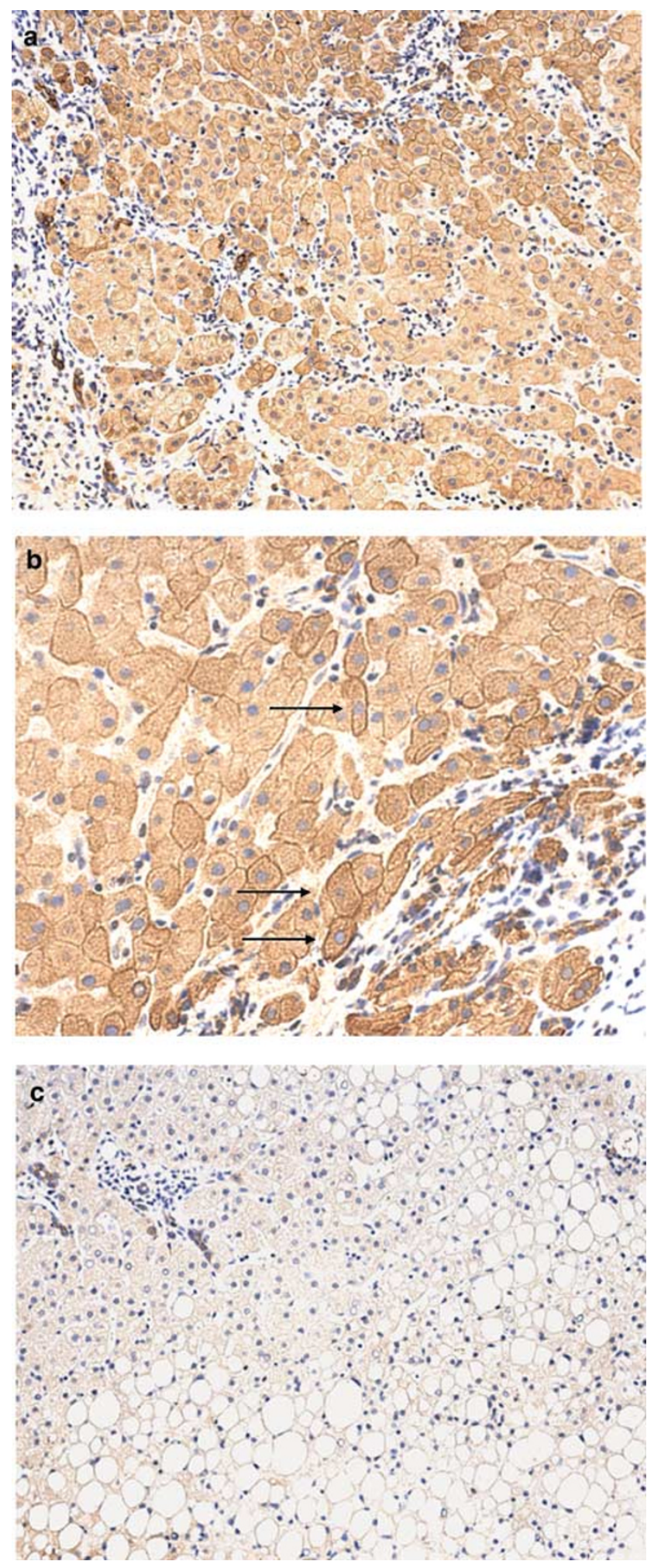

of well-differentiated hepatocellular carcinoma were HBx-positive in more than $30 \%$ of tumor cells (Figure 2c). In contrast, HBx was undetectable or present in less than $30 \%$ of tumor cells in over $80 \%$ of poorly differentiated hepatocellular carcinoma (Figure 2d). There was a close correlation between HBx immunoreactivity and differentiation status of hepatocellular carcinoma specimens ( $\mathrm{rs}=-0.49$, $P=0.019$ ).

COX-2 expression was also detected in all specimens of chronic hepatitis B and cirrhosis but only in $78 \%(18 / 23)$ of hepatocellular carcinoma by immunohistochemistry (Table 2). All well- and moderately differentiated hepatocellular carcinoma expressed COX-2 but only 29\% (2/7) of poorly differentiated hepatocellular carcinoma had COX-2 expression. In accordance with previous studies, COX-2 immunoreactivity was found to have significant correlation with hepatocellular carcinoma differentiation ( $\mathrm{rs}=-0.81, P<0.001$ ). When comparing $\mathrm{HBx}$ and COX-2 expressions in different hepatitis $\mathrm{B}$ virus-associated chronic liver diseases, significant correlations were found in all types including chronic hepatitis $\mathrm{B}$ ( $\mathrm{rs}=0.68, P=0.021$ ), cirrhosis ( $\mathrm{rs}=0.57, P=0.004$ ), and hepatocellular carcinoma ( $\mathrm{rs}=0.45, P=0.031$ ).

To further characterize the relationship between HBx and COX-2, serial sections of liver specimens were stained for both antigens. COX-2 staining was mainly found in the cytoplasm of hepatocytes in the cirrhotic lobule (Figure 3a). Consecutive section stained for $\mathrm{HBx}$ also demonstrated cytoplasmic staining in the hepatocytes (Figure 3b). Double immunostaining on the serial section showed that HBx and COX-2 colocalized in some hepatocytes of the lobule (Figure 3c).

\section{Effects of Antiviral Therapies on $\mathrm{HBx}$ and COX-2 Expression}

HBx immunostaining was performed on the pre- and post-treatment chronic hepatitis B specimens. Albeit having marked reductions in the necro-inflammatory activities after antiviral therapies (Table 3), HBx immunoreactivity was still detectable in the hepatic lobules after interferon or lamivudine treatment (Figure 4). There was also no noticeable

Figure 1 Representative microphotographs of HBx immunohistochemistry in hepatitis B virus-associated chronic liver diseases and nonalcoholic steato-hepatitis patients. (a) Immunohistochemical staining of $\mathrm{HBx}$ revealed diffuse positivity in the hepatocytes throughout the lobule of a chronic hepatitis B patient. The inflammatory cells in the portal region were negative (original magnification, $\times 200$ ). (b) HBx immunoreactivity was observed in the cytoplasm of the hepatocytes of a chronic hepatitis B patient. Membranous staining of HBx in hepatocytes (arrows) was also detected (original magnification, $\times 400$ ). (c) No HBx immunoreactivity could be observed in the hepatic lobule of a nonalcoholic steato-hepatitis patient except nonspecific reaction in the bile ductules (original magnification, $\times 200$ ). 

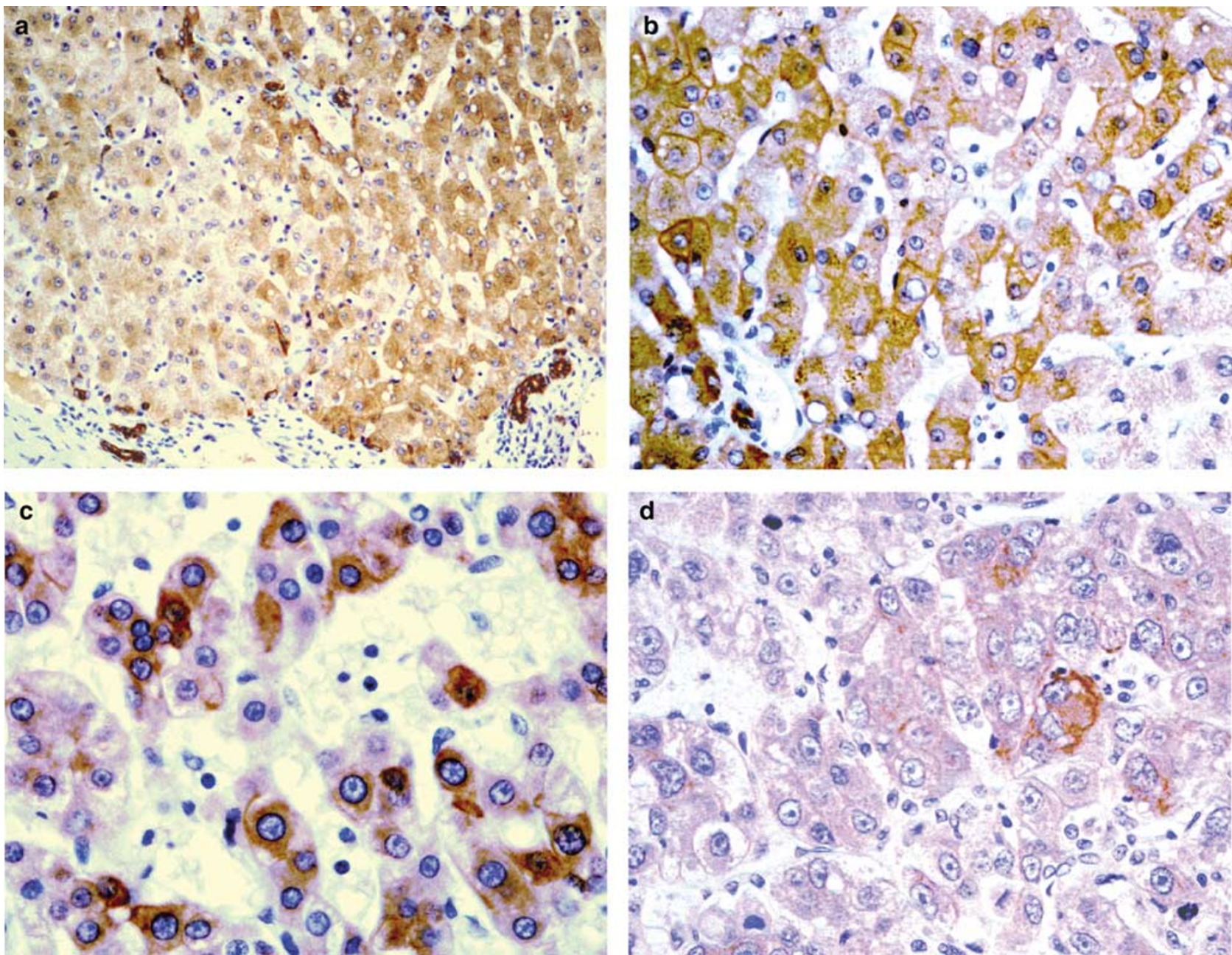

Figure 2 Immunohistochemical detection of HBx in cirrhosis and hepatocellular carcinoma specimens. (a) and (b) Immunohistochemical staining for HBx in a hepatitis B virus-associated cirrhosis specimens. Cytoplasmic staining of hepatocytes with HBx was observed (a, original magnification, $\times 200$; b, original magnification, $\times 400)$. (c) More intense and widespread HBx immunoreactivity was observed in the cytoplasm of tumor cells in a well-differentiated hepatocellular carcinoma (original magnification, $\times 400$ ). (d) Only weak and focal immunoreactivity could be observed in tumor cells in a poorly differentiated hepatocellular carcinoma (original magnification, $\times 400)$.

Table 3 Immunohistochemical and histological scores of chronic hepatitis B patients upon antiviral treatments

\begin{tabular}{|c|c|c|c|c|c|c|c|c|c|}
\hline \multirow[t]{2}{*}{ Patient } & \multirow[t]{2}{*}{ Treatment } & \multicolumn{2}{|c|}{$H B x$} & \multicolumn{2}{|c|}{$C O X-2$} & \multicolumn{2}{|c|}{ Necro-inflammatory score } & \multicolumn{2}{|c|}{ Fibrosis score } \\
\hline & & Pre- & Post- & Pre- & Post- & Pre- & Post- & Pre- & Post- \\
\hline 1 & Interferon & 5 & 3 & 4 & 5 & 8 & 4 & 1 & 1 \\
\hline 2 & Interferon & 4 & 4 & 4 & 5 & 5 & 2 & 1 & 1 \\
\hline 3 & Interferon & 3 & 4 & 4 & 5 & 5 & 1 & 3 & 1 \\
\hline 4 & Interferon & 4 & 2 & 5 & 5 & 6 & 2 & 1 & 0 \\
\hline 5 & Interferon & 5 & 4 & 5 & 5 & 9 & 3 & 1 & 1 \\
\hline 6 & Lamivudine & 5 & 3 & 5 & 3 & 11 & 1 & 1 & 1 \\
\hline $7^{\mathrm{a}}$ & Lamivudine & 3 & 3 & 4 & 5 & - & - & - & - \\
\hline 8 & Lamivudine & 2 & 4 & 4 & 5 & 5 & 2 & 1 & 1 \\
\hline 9 & Lamivudine & 5 & 3 & 5 & 4 & 11 & 2 & 1 & 1 \\
\hline 10 & Lamivudine & 2 & 3 & 4 & 3 & 9 & 2 & 1 & 1 \\
\hline \multirow[t]{3}{*}{11} & Lamivudine & 3 & 2 & 4 & 4 & 11 & 1 & 1 & 0 \\
\hline & Median (range) & $4(2-5)$ & $3(2-4)$ & $4(4-5)$ & $5(3-5)$ & $8.5(5-11)$ & $2(1-4)$ & $1(1-3)$ & $1(0-1)$ \\
\hline & $P$ & \multicolumn{2}{|c|}{0.27} & \multicolumn{2}{|c|}{0.56} & \multicolumn{2}{|c|}{$<0.001$} & \multicolumn{2}{|c|}{0.32} \\
\hline
\end{tabular}

Both HBx and COX-2 immunohistochemical scores were based on intensity and extensiveness (by percentage population) of the positively stained cells.

${ }^{\mathrm{a}}$ This specimen has inadequate tissue for histological scoring. 

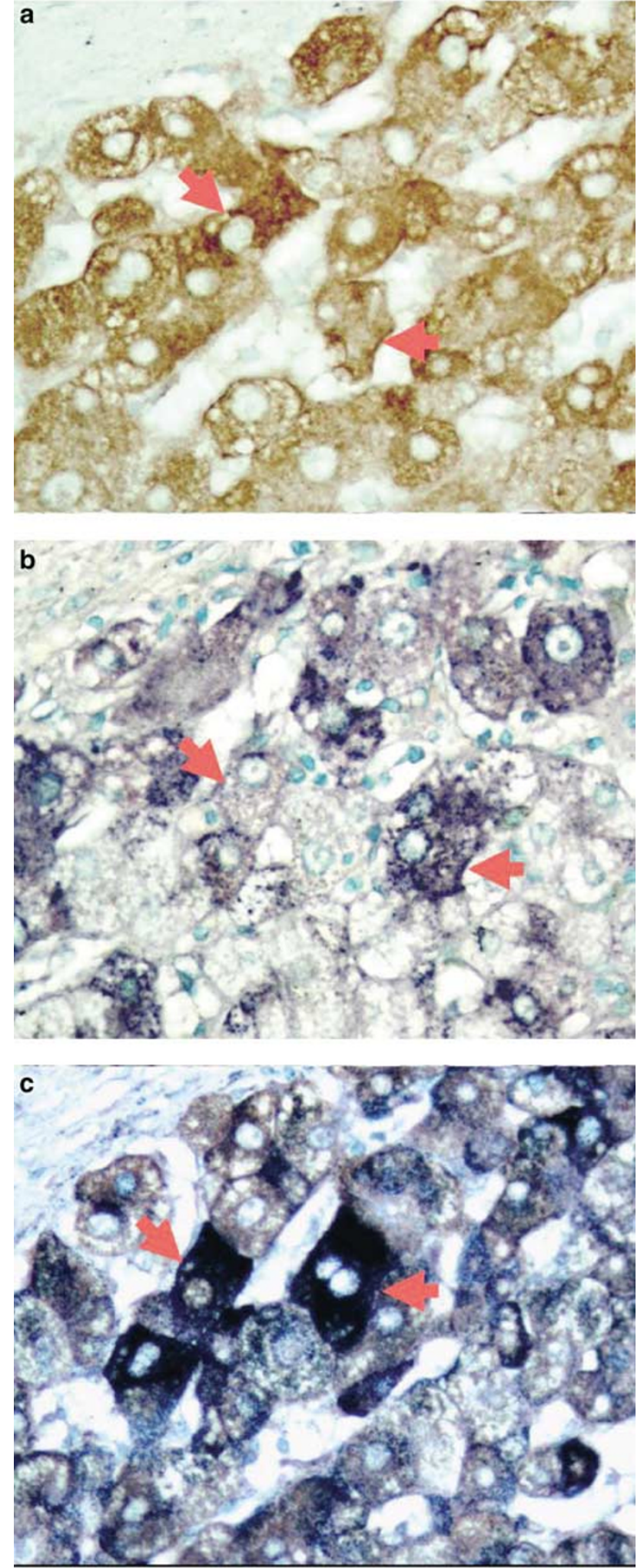

Figure 3 Immunohistochemical detection of HBx and COX-2 in liver specimens. (a) and (b) Consecutive sections of a cirrhosis specimen were stained for COX-2 (a, original magnification, $\times 400)$ and HBx (b, original magnification, $\times 400)$. Examples of coexpression of both HBx and COX-2 in hepatocytes were indicated by arrows. (c) Double staining with both antibodies highlighted the coexpression of $\mathrm{HBx}$ and $\mathrm{COX}-2$ in some hepatocytes (indicated by arrows) (original magnification, $\times 400$ ). change in $\mathrm{HBx}$ cellular distribution. HBx expression decreased in $55 \%(6 / 11)$ of chronic hepatitis $B$ patients after therapies, increased in $27 \%(3 / 11)$ and remained unchanged in 18\% (2/11) (Table 3). Similar to COX-2, there was no significant change in HBx expression after successful antiviral therapy $(P=0.27$, Table 3$)$.

\section{HBx Induced COX-2 Gene Expression}

To determine whether $\mathrm{HBx}$ might induce $C O X-2$ gene expression, the pcDNA3-HBx plasmid was transiently transfected into the Hep3B hepatocellular carcinoma cells, which had only minimal COX-2 expression. RT-PCR and Western blot analyses showed that $H B x$ mRNA and protein were expressed in HBx-transfected cells, whereas no signal could be detected from cells transfected with empty vector at $48 \mathrm{~h}$ post-transfection (Figure 5a). HBx-transfected cells showed elevated $C O X-2$ mRNA level when compared with sham-transfected cells (Figure 5b). To evaluate the enzyme activity, prostaglandin $\mathrm{E}_{2}$ levels in culture supernatant were measured by enzyme immunoassay. The prostaglandin $\mathrm{E}_{2}$ level of HBx-transfected cells was $136 \pm 18 \%$ higher than that of sham-transfected cells, based on normalization to protein amount in three independent experiments.

The subcellular distribution of HBx in Hep3B hepatocellular carcinoma cells was investigated by means of the EGFP reporter. At $24 \mathrm{~h}$ post-transfection, the EGFP-HBx fusion protein was found diffusely throughout the cytoplasm (Figure 6a) as well as in the perinuclear region of Hep3B cells (Figure 6b). In the control, EGFP expressed from empty vector was found throughout the whole cell without specific distribution (Figure 6c). At $48 \mathrm{~h}$ post-transfection, in addition to the cytoplasm, the EGFP-HBx fusion protein could also be found in the nuclei of some cells (Figure 6d and e).

\section{Discussion}

HBx functions as a transcriptional activator that is required for viral infection and contributes to hepatitis B virus-associated hepatocarcinogenesis. ${ }^{19}$ Although the transactivation function of $\mathrm{HBx}$ has been repeatedly inferred as an important carcinogenic factor, downstream effectors remain to be identified. In this study, we have demonstrated a concomitant expression pattern of $\mathrm{HBx}$ and $\mathrm{COX}-2$ in hepatitis B virus-associated chronic liver diseases. First, HBx and COX-2 had similar expression rates and correlated strongly with each other in chronic hepatitis B, cirrhosis, and hepatocellular carcinoma. Among hepatocellular carcinoma specimens, both expression levels correlated significantly with the differentiation status. Second, immunohistochemical double staining has shown colocalization of $\mathrm{HBx}$ and $\mathrm{COX}-2$ in hepatic parenchymal 

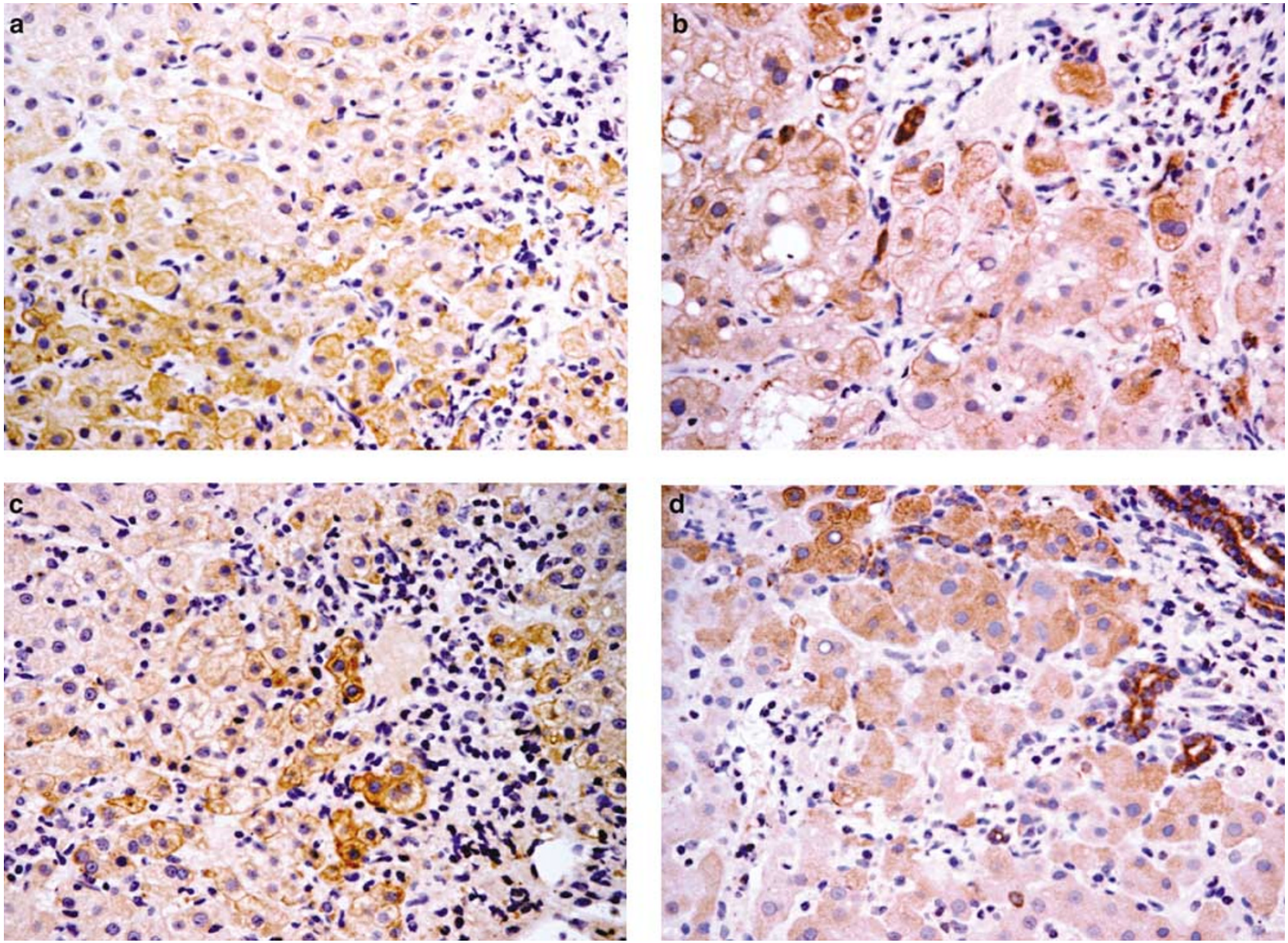

Figure 4 Representative microphotographs of HBx immunohistochemistry in liver biopsy specimens of chronic hepatitis B patients preand post-treatment with interferon (a) and (b) or lamivudine (c) and (d) (original magnification, $\times 200$ ). Although the inflammation was subsided after treatment, both the pre- and post-treatment biopsies demonstrated HBx immunoreactivity in the hepatocytes. Intense staining on bile ducts was nonspecific and attributed to crossreactivity to cytokeratin 18.

a

HBx mRNA

HBx pcDNA3

HBx protein

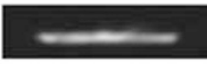

$\longleftarrow 485$ bp

b

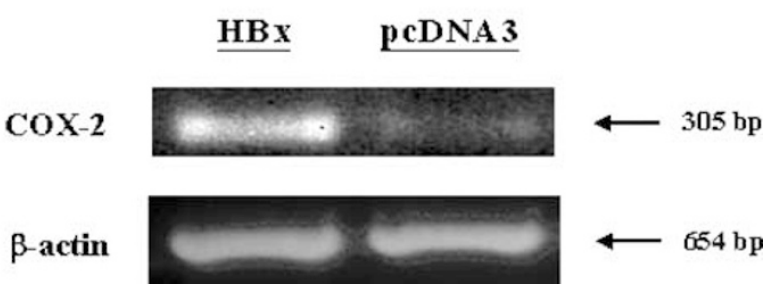

Figure 5 COX-2 expression of Hep3B hepatocellular carcinoma cells after $\mathrm{HBx}$ transfection. (a) At $48 \mathrm{~h}$ post-transfection, $\mathrm{HBx}$ mRNA and protein were expressed as shown by using RT-PCR and Western blot analyses, respectively. (b) COX-2 mRNA was upregulated in HBx-transfected cells when compared with shamtransfected cells. $\beta$-Actin was also amplified to assess the equality of RNA amount in both samples. Representative pictures of two independent experiments were shown. cells. Third, expression of both proteins persisted in liver specimens of chronic hepatitis B patients who responded to antiviral therapies. Taken together with the finding that $\mathrm{HBx}$ induced $C O X-2$ gene in vitro, our results strongly suggest a causal relationship between HBx and COX-2.

HBx has been suggested to be a dual specific activator of transcription, acting on signal transduction pathways in the cytoplasm and transcription factors in the nucleus. ${ }^{20}$ In the current study, $\mathrm{HBx}$ was found in the cytoplasm and occasionally nuclei of both hepatitis B virus-infected liver cells in vivo and HBx-transfected cells in vitro. The cytoplasmic localization of $\mathrm{HBx}$ in liver cells ${ }^{17,21}$ implies that HBx may mainly alter signal transduction pathways in chronic liver diseases. HBx is able to activate nuclear factor- $\kappa B$, Ras, Raf, MAP kinase, and SAPK/ JNK signaling pathways. ${ }^{22-24}$ On the other hand, the cis-acting elements activated by these pathways are present in the COX-2 gene promoter and have been rigorously demonstrated to regulate $C O X-2$ transcription. ${ }^{25-27} \mathrm{HBx}$ present in the nucleus, although 

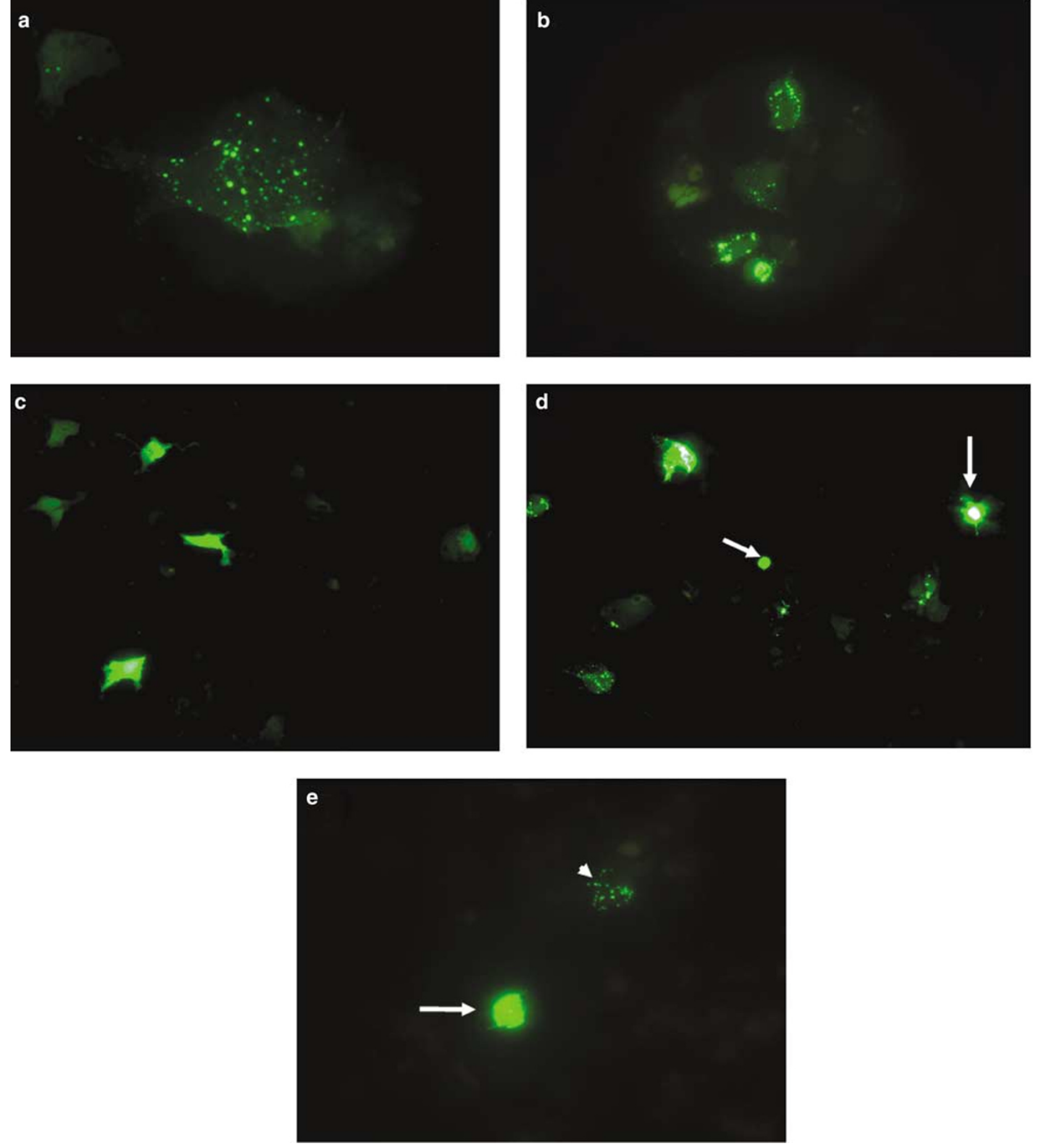

Figure 6 Subcellular distribution of EGFP-HBx fusion protein in Hep3B hepatocellular carcinoma cells as viewed by fluorescent microscopy. (a) Diffuse cytoplasmic granular staining of EGFP-HBx was observed (original magnification, $\times 1000$ ). (b) Perinuclear punctuate granular positivity was detected at $24 \mathrm{~h}$ post-transfection (original magnification, $\times 400$ ). (c) In the control experiment, EGFP was found throughout the whole cell (original magnification, $\times 200$ ). (d) In addition to the cytoplasmic positivity, nuclear signals of EGFP-HBx could also be seen in some cells (arrows) at $48 \mathrm{~h}$ post-transfection (original magnification, $\times 200$ ). (e) Both cytoplasmic (arrowhead) and nuclear (arrow) signals of EGFP-HBx were shown at $48 \mathrm{~h}$ post-transfection (original magnification, $\times 400$ ).

in a less extent, may also regulate $C O X-2$ expression through its interaction with cyclic AMP response element binding protein. ${ }^{28} \mathrm{~A}$ recent study has reported that $C O X-2$ could be transcriptionally upregulated by $\mathrm{HBx}$ via the nuclear factor of activated T cells (NF-AT) binding site of the COX-2 promoter. $^{29}$ Taken together, it is conceivable that hepatocellular COX-2 gene expression might be 
transcriptionally upregulated by $\mathrm{HBx}$ in chronic liver diseases.

Since all chronic hepatitis B patients in this study were $\mathrm{HBeAg}$ positive with high hepatitis $\mathrm{B}$ virus DNA titer prior to treatment, one may expect to see high HBx expression in hepatocytes. However, we also showed that HBx expression persisted even after $\mathrm{HBeAg}$ sero-conversion, clearance of hepatitis $B$ virus-DNA, and normalization of liver enzymes secondary to lamivudine or interferon therapy. This is the first report demonstrating expression of $\mathrm{HBx}$ after antiviral treatments. Although viral clearance may downregulate $\mathrm{HBx}$, the integrated viral DNA template in the host genome may be the main source for the persistent HBx expression. This hypothesis is supported by previous observations stating that functional $\mathrm{HBx}$ can be produced from hepatitis $\mathrm{B}$ virus DNA-integrated genomes. ${ }^{30,31} \mathrm{HBx}$ expressed in the post-treatment liver specimens of chronic hepatitis B patients may be the cause of sustained hepatocellular COX-2 expression even after the inflammation has subsided. ${ }^{14}$

Since COX-2 expression could be detected in liver cells in the absence of HBx (Figure 3a and b), other stimulus for hepatocellular COX-2 production may exist. COX-2 has been shown to be induced by hypoxia ${ }^{32}$ which was also involved in angiogenesis of hepatocellular carcinoma. ${ }^{33}$ There was active hepatitis present in some hepatocellular carcinoma tissues. Inflammatory cytokines like tumor necrosis factor $\alpha$ may thus stimulate COX-2 upregulation. Therefore, regulation of COX-2 expression in liver cells might be multifactorial. High COX-2 expression has been demonstrated in hepatitis $\mathrm{C}$ virus-related chronic hepatitis and hepatocellular carcinoma by a previous study. ${ }^{13}$ It would be interesting to investigate if viral factor of hepatitis $\mathrm{C}$ virus, for example, core protein is capable of inducing COX-2 expression.

In order to maintain chronic infection, hepatitis B virus has to develop strategies to promote survival of the infected liver cells against host immune response. In this sense, HBx has been found to protect liver cells from Fas-mediated apoptosis. ${ }^{24,34}$ On the other hand, we $^{35}$ and other investigators ${ }^{36}$ have demonstrated that COX-2 promotes the growth of the hepatoma cell lines by inhibiting apoptosis and inducing proliferation. A recent study has shown that COX-2 inhibits Fas-mediated apoptosis of cholangiocarcinoma cells. ${ }^{37}$ COX-2 also inhibits immune surveillance by shifting Th1/Th2 balance to a Th2-predominant status. ${ }^{38}$ Thus, COX-2 upregulation may contribute to the persistence of infected hepatocytes during chronic hepatitis B. The sustained HBx and COX-2 coexpression over prolonged period from chronic infection to cirrhosis may cause uncontrolled growth, placing large numbers of hepatocytes susceptible to secondary events for neoplastic transformation leading to hepatocellular carcinoma. Our data suggest that HBx and COX-2 may participate in one or more critical steps important to the establishment of liver cancer.

In conclusion, we have demonstrated coexpression of $\mathrm{HBx}$ and $\mathrm{COX}-2$ in hepatitis $\mathrm{B}$ virusassociated chronic liver diseases. Given the multicarcinogenic properties of COX-2, the experimental evidence that HBx induces $C O X-2$ gene expression in liver cells provides a clue by which hepatitis B virus increases the risk of liver cancer. Further studies are warranted to evaluate the use of COX-2specific inhibitors on hepatocellular carcinoma chemoprevention.

\section{Acknowledgement}

This study was supported by the Cheng Suen Man Shook Foundation for Hepatitis Studies.

\section{References}

1 Beasley RP, Hwang LY, Lin CC, et al. Hepatocellular carcinoma and hepatitis B virus. A prospective study of 22707 men in Taiwan. Lancet 1981;2:1129-1133.

2 Hohne M, Schaefer S, Seifer M, et al. Malignant transformation of immortalized transgenic hepatocytes after transfection with hepatitis B virus DNA. EMBO J 1990;9:1137-1145.

3 Koike K, Moriya K, Iino S, et al. High-level expression of hepatitis B virus HBx gene and hepatocarcinogenesis in transgenic mice. Hepatology 1994;19:810-819.

4 Madden CR, Finegold MJ, Slagle BL. Hepatitis B virus $\mathrm{X}$ protein acts as a tumor promoter in development of diethylnitrosamine-induced preneoplastic lesions. J Virol 2001;75:3851-3858.

5 Dubois RN, Abramson SB, Crofford L, et al. Cyclooxygenase in biology and disease. FASEB J 1998;12: 1063-1073.

6 Ebherhat CE, Coffey RJ, Radhika A, et al. Up-regulation of cyclooxygenase-2 gene expression in human colorectal adenomas and adenocarcinomas. Gastroenterology 1994;107:1183-1188.

7 Tucker ON, Dannenberg AJ, Yang EK, et al. Cyclooxygenase-2 expression is up-regulated in human pancreatic cancer. Cancer Res 1999;59:987-990.

8 Shirvani VN, Ouatu-Lascar R, Kaur BS, et al. Cyclooxygenase 2 expression in Barrett's esophagus and adenocarcinoma: ex vivo induction by bile salts and acid exposure. Gastroenterology 2000;118:487-496.

9 Sung JJ, Leung WK, Go MY, et al. Cyclooxygenase-2 expression in Helicobacter pylori-associated premalignant and malignant gastric lesions. Am J Pathol 2000;157:729-735.

10 Oshima M, Dinchuk JE, Kargman SL, et al. Suppression of intestinal polyposis in Apc delta716 knockout mice by inhibition of cyclooxygenase 2 (COX-2). Cell 1996;87:803-809.

11 Liu CH, Chang SH, Narko K, et al. Overexpression of cyclooxygenase-2 is sufficient to induce tumorigenesis in transgenic mice. J Biol Chem 2001;276:1856318569.

12 Koga H, Sakisaka S, Ohishi M, et al. Expression of cyclooxygenase-2 in human hepatocellular carcinoma: 
relevance to tumor dedifferentiation. Hepatology 1999;29:688-696.

13 Kondo $\mathrm{M}$, Yamamoto $\mathrm{H}$, Nagano $\mathrm{H}$, et al. Increased expression of COX-2 in nontumor liver tissue is associated with shorter disease-free survival in patients with hepatocellular carcinoma. Clin Cancer Res 1999;5:4005-4012.

14 Cheng AS, Chan HL, Leung NW, et al. Expression of Cyclooxygenase-2 in chronic hepatitis $\mathrm{B}$ and the effects of anti-viral therapies. Aliment Pharmacol Ther 2002;16:251-260.

15 Liver Cancer Study Group of Japan. Primary liver cancer in Japan. Clinicopathologic features and results of surgical treatment. Ann Surg 1990;211:277-287.

16 Knodell RG, Ishak KG, Black WC, et al. Formulation and application of a numerical scoring system for assessing histological activity in asymptomatic chronic active hepatitis. Hepatology 1981;1:431-435.

17 Wang WL, London WT, Lega L, et al. HBxAg in the liver from carrier patients with chronic hepatitis and cirrhosis. Hepatology 1991;14:29-37.

$18 \mathrm{Su}$ Q, Schroder CH, Hofmann WJ, et al. Expression of hepatitis $\mathrm{B}$ virus $\mathrm{X}$ protein in $\mathrm{HBV}$-infected human livers and hepatocellular carcinomas. Hepatology 1998;27:1109-1120.

19 Feitelson MA, Duan LX. Hepatitis B virus X antigen in the pathogenesis of chronic infections and the development of hepatocellular carcinoma. Am J Pathol 1997;150:1141-1157.

20 Doria M, Klein N, Lucito R, et al. The hepatitis B virus $\mathrm{HBx}$ protein is a dual specificity cytoplasmic activator of Ras and nuclear activator of transcription factors. EMBO J 1995;14:4747-4757.

21 Hoare J, Henkler F, Dowling JJ, et al. Subcellular localisation of the X protein in HBV infected hepatocytes. J Med Virol 2001;64:419-426.

22 Benn J, Schneider RJ. Hepatitis B virus HBx protein activates Ras-GTP complex formation and establishes a Ras, Raf, MAP kinase signaling cascade. Proc Natl Acad Sci USA 1994;91:10350-10354.

$23 \mathrm{Su} \mathrm{F}$, Schneider RJ. Hepatitis B virus HBx protein activates transcription factor NF-kappaB by acting on multiple cytoplasmic inhibitors of rel-related proteins. J Virol 1996;70:4558-4566.

24 Diao J, Khine AA, Sarangi F, et al. X protein of hepatitis B virus inhibits Fas-mediated apoptosis and is associated with upregulation of the SAPK/JNK pathway. J Biol Chem 2001;276:8328-8340.

25 Smith WL, DeWitt DL, Garavito RM. Cyclooxygenases: structural, cellular, and molecular biology. Annu Rev Biochem 2000;69:145-182.

26 Mestre JR, Mackrell PJ, Rivadeneira DE, et al. Redundancy in the signaling pathways and promoter elements regulating cyclooxygenase-2 gene expression in endotoxin-treated macrophage/monocytic cells. J Biol Chem 2001;276:3977-3982.

27 Guan Z, Buckman SY, Miller BW, et al. Interleukin1beta-induced cyclooxygenase-2 expression requires activation of both c-Jun NH2-terminal kinase and p38 MAPK signal pathways in rat renal mesangial cells. J Biol Chem 1998;273:28670-28676.

28 Maguire HF, Hoeffler JP, Siddiqui A. HBV X protein alters the DNA binding specificity of CREB and ATF-2 by protein-protein interactions. Science 1994;252: 842-844.

29 Lara-Pezzi E, Gomez-Gaviro MV, Galvez BG, et al. The hepatitis $\mathrm{B}$ virus $\mathrm{X}$ protein promotes tumor cell invasion by inducing membrane-type matrix metalloproteinase-1 and cyclooxygenase-2 expression. J Clin Invest 2002;110:1831-1838.

30 Wollersheim M, Debelka U, Hofschneider PH. A transactivating function encoded in the hepatitis B virus $X$ gene is conserved in the integrated state. Oncogene 1988;3:545-552.

31 Takada S, Koike K. trans-Activation function of a $3^{\prime}$ truncated $X$ gene-cell fusion product from integrated hepatitis B virus DNA in chronic hepatitis tissues. Proc Natl Acad Sci USA 1990;87:5628-5632.

32 Schmedtje Jr JF, Ji YS, Liu WL, et al. Hypoxia induces cyclooxygenase-2 via the NF-kappaB p65 transcription factor in human vascular endothelial cells. J Biol Chem 1997;272:601-608.

33 von Marschall Z, Cramer T, Hocker M, et al. Dual mechanism of vascular endothelial growth factor upregulation by hypoxia in human hepatocellular carcinoma. Gut 2001;48:87-96.

34 Pan J, Duan LX, Sun BS, et al. Hepatitis B virus X protein protects against anti-Fas-mediated apoptosis in human liver cells by inducing NF-kappa B. J Gen Virol 2001;82:171-182.

35 Cheng AS, Chan HL, Leung WK, et al. Specific COX-2 inhibitor, NS-398, suppresses cellular proliferation and induces apoptosis in human hepatocellular carcinoma cells. Int J Oncol 2003;23:113-119.

36 Bae SH, Jung ES, Park YM, et al. Expression of cyclooxygenase-2 (COX-2) in hepatocellular carcinoma and growth inhibition of hepatoma cell lines by a COX-2 inhibitor, NS-398. Clin Cancer Res 2001;7: 1410-1418.

37 Nzeako UC, Guicciardi ME, Yoon JH, et al. COX-2 inhibits Fas-mediated apoptosis in cholangiocarcinoma cells. Hepatology 2002;35:552-559.

38 Huang M, Stolina M, Sharma S, et al. Non-small cell lung cancer cyclooxygenase-2-dependent regulation of cytokine balance in lymphocytes and macrophages: up-regulation of interleukin 10 and down-regulation of interleukin 12 production. Cancer Res 1998;58: 1208-1216. 